\title{
Side Effects of Chloroquine and Primaquine and Symptom Reduction in Malaria Endemic Area (Mâncio Lima, Acre, Brazil)
}

\author{
Cássio Braga e Braga, Antonio Camargo Martins, Athaid David Escalante Cayotopa, \\ Wagner Werner Klein, Andreus Roberto Schlosser, Aline Ferreira da Silva, \\ Mardelson Nery de Souza, Breno Wilson Benevides Andrade, \\ José Alcântara Filgueira-Júnior, Wagner de Jesus Pinto, and Mônica da Silva-Nunes
}

\begin{abstract}
Centro de Ciências da Saúde e do Desporto, Universidade Federal do Acre, Campus Universitário, BR 364, Km 04,
\end{abstract} 69920-900 Rio Branco, AC, Brazil

Correspondence should be addressed to Mônica da Silva-Nunes; msnunes1@yahoo.com.br

Received 31 May 2015; Revised 3 August 2015; Accepted 5 August 2015

Academic Editor: Stéphane Picot

Copyright (C) 2015 Cássio Braga e Braga et al. This is an open access article distributed under the Creative Commons Attribution License, which permits unrestricted use, distribution, and reproduction in any medium, provided the original work is properly cited.

Side effects of antimalarial drug can overlap with malaria symptoms. We evaluated 50 patients with vivax malaria in Mâncio Lima, Acre, treated with chloroquine and primaquine. Patients were evaluated for the presence of 21 symptoms before and after treatment and for reported side effects of these drugs after treatment was started. The most frequent symptoms before medication were headache, fever, chills, sweating, arthralgia, back pain, and weakness, which were present in between $40 \%$ and $76 \%$ of respondents. The treatment reduced the occurrence of these symptoms and reduced the lack of appetite, but gastrointestinal symptoms and choluria increased in frequency. There were no reports of pale stools before medication, but $12 \%$ reported the occurrence of this symptom after treatment started. Other symptoms such as blurred vision (54\%), pruritus (22\%), paresthesia (6\%), insomnia (46\%), and "stings" into the skin (22\%) were reported after chloroquine was taken. The antimalarial drugs used to treat $P$. vivax malaria reduce much of the systemic and algic symptoms but cause mainly gastrointestinal side effects that may lead to lack of adherence to drug treatment. It is important to guide the patient for the appearance and the transience of such side effects in order to avoid abandoning treatment.

\section{Introduction}

Malaria is one of the main scourges of the world, affecting half a million people a year [1]. It is caused by parasites belonging to the phylum Apicomplexa, family Plasmodiidae, and genus Plasmodium. There are five known species that parasitize man, the most prevalent being Plasmodium falciparum, $P$. vivax, and $P$. malariae in tropical areas such as Latin America, the Indian subcontinent, Southeast Asia, and parts of Africa [2]. P. ovale has been reported in Africa, Middle East, and the Indian subcontinent [3], while P. knowlesi has been recently described as responsible for large foci of infections in Southeast Asia [4]. The natural transmission occurs through the bite of infected female Anopheles mosquito, Anopheles darlingi being the most prevalent species in the country [5].
The Ministry of Health directs therapy and provides free antimalarial medicines used throughout the national territory, in units of the Unified Health System (SUS), through a national policy on malaria treatment. Malaria caused by $P$. vivax (or P. ovale) is treated with chloroquine in Brazil at a dose of $30 \mathrm{mg} / \mathrm{kg}$ divided into three days and primaquine in the $30 \mathrm{mg}$ dose/day for 7 days or $15 \mathrm{mg} /$ day for 14 days. Also, low doses of chloroquine can be used for the prevention of vivax malaria. Pregnant women and children under 6 months of age with vivax malaria receive only chloroquine in different dosage schedules [6].

Primaquine is the only antimalarial drug with effective activity against all the species gametocytes of Plasmodium which cause malaria in humans, as well as against hypnozoites, latent forms of $P$. vivax and $P$. ovale responsible for relapses [7]. However, it has hemolytic effects, especially in 
people with glucose-6-phosphate dehydrogenase deficiency (G6PD), in which primaquine as a stressor to the erythrocyte induces hemolysis. Hemolysis induced by primaquine can result in discoloration of urine and faeces and it is dose related $[8,9]$. Gastrointestinal disorders, such as nausea, dizziness, and vomiting, are common but usually not present as severe complications, especially when primaquine is administered with food. Hypersensitivity reactions can also occur but are rare [10].

With respect to chloroquine, there are relatively few adverse effects with use in usual doses, of which the most serious are retinopathy, cardiomyopathy, myopathy, and neuromyopathy. Prolonged treatment or use of high level doses may cause retinal toxicity, long subtle symptoms of decreased visual acuity, diplopia, and bilateral loss of vision [11]. Adverse reactions of the gastrointestinal tract are the most common side effects, usually controlled by reducing drug dose. There are also reports of ototoxicity, tingling, itching, and change in skin color, in addition to seizures, insomnia, and paresthesia $[12,13]$.

The occurrence of symptoms specifically related to the intake of antimalarials and the overlap of symptoms of malaria with the side effects of primaquine and chloroquine may decrease adherence to treatment. Therefore, it becomes important to assess the main side effects of antimalarial drugs in patients from endemic areas, where treatment is aimed not only at improving the clinical status but also at reducing the transmission of Plasmodium. This study evaluated the frequency of the symptoms that commonly occur in vivax malaria before and after treatment and the frequency of side effects reported during the term of antimalarial treatment with chloroquine and primaquine in standardized doses according to the protocol of the Brazilian Ministry of Health [6].

\section{Materials and Methods}

2.1. Study Area. The study was conducted in the urban area of the municipality of Mâncio Lima, located in the Western part of the Brazilian Amazon, in the state of Acre. This municipality, with $5000 \mathrm{~km}^{2}$, is bordered by the cities of Cruzeiro do Sul and Rodrigues Alves and the Republic of Peru. Mâncio Lima has 14,884 inhabitants living in urban areas $(57.3 \%)$, rural or riparian areas $(37.9 \%)$, and Indian villages $(4.8 \%)$. The county is located $38 \mathrm{~km}$ from Cruzeiro do Sul and $650 \mathrm{~km}$ from Rio Branco.

\subsection{Study Population, Study Design, and Sampling Techniques.} Patients with microscopic diagnosis of vivax malaria were identified in microscopy stations of the city of Mâncio Lima before the medication and invited to participate in the study. Data collection took place between May and June 2013. After signing the informed consent or having it signed by parents or legal guardians, patients answered a questionnaire on malaria symptoms that occurred up to the time of diagnosis (before antimalarial treatment), to verify the occurrence of the following symptoms: nausea, vomiting, diarrhea, pale stools, loss of appetite, mesogastric and/or hypogastric pain, pain in hypochondrium, headache, myalgia, arthralgia, back pain, retroocular pain, fever, chills, sweating, malaise or weakness, itchy throat, jaundice, choluria, dyspnea, and bitter taste sensation, covering up thereby symptoms commonly occurring in malaria and overlapping with possible side effects of chloroquine and primaquine. Between 3 and 5 days after the start of medication, a second interview was conducted asking about the occurrence of the same symptoms plus some symptoms related to the use of chloroquine that are infrequent in malaria: blurred vision, itching, stinging sensation of the skin, convulsions, numbness, and insomnia.

2.3. Data Analysis. The data was entered into SPSS. The distributions of relative and absolute frequencies, median, mean, and standard deviations of the variables of interest were calculated. As primaquine and chloroquine may lead to the onset of symptoms and also intensify or reduce some of the symptoms of malaria, the occurrence of symptoms before and after drug treatment was analyzed with the McNemar's test for paired samples. Some of the symptoms considered to be side effects of chloroquine and primaquine and that are not usual in malaria were assessed only after drug treatment was started.

2.4. Ethical Aspects. The research protocol was submitted to the Ethics Committee for Experimentation with Human Beings of Universidade Federal do Acre and approved, CAE number 22876013.9.0000.5010 (2013). Informed consent was obtained from each adult participant or legal guardian in case of minors, before the start of the study.

\section{Results}

3.1. Patient Characteristics. The study included 50 people with vivax malaria, 28 men and 22 women, aged between 7 and 68 years (average age 28.38 years). The average length of stay in an endemic area was 24.79 years, and about one-third of the study population (30\%) lived in an endemic area for malaria between 11 and 20 years.

Of the 50 patients evaluated, only one had a primary infection, and all the others had had between 1 and 41 episodes of previous malaria, and 36\% report having had more than 10 episodes of malaria. About $52 \%$ had an episode in the 12 months leading up to the current episode, ranging from one to 10, the number of malaria events in 2012. Most of the patients had low parasitemia (less than 200 parasites $/ \mathrm{mm}^{3}$ in $66 \%$ of cases), $12 \%$ of them had between 301 and 500 parasites $/ \mathrm{mm}^{3}$, and $12 \%$ were found to have 50110000 parasites $/ \mathrm{mm}^{3}$ (Table 1 ).

3.2. Frequency of Symptoms before and after Medication. The main symptoms observed in untreated malaria were fever (72\%), chills (54\%), sweating (54\%), and weakness (42\%), as well as pain symptoms including headache (76\%), arthralgia (48\%), and lower back pain (52\%). Less commonly reported symptoms were retroocular pain (36\%) and myalgia (30\%). Gastrointestinal symptoms occurred in low frequency, such as bitter taste $(30 \%)$, decreased appetite (32\%), nausea (22\%), vomiting (16\%), and pain in hypogastric or mesogastric 
TABLE 1: Epidemiological and clinical variables of the study population.

\begin{tabular}{|c|c|}
\hline \multicolumn{2}{|c|}{ Clinical and epidemiological characteristics (\%) } \\
\hline \multicolumn{2}{|l|}{ Gender } \\
\hline Male & $56 \%$ \\
\hline Female & $44 \%$ \\
\hline \multicolumn{2}{|l|}{ Age } \\
\hline 0 to 15 years old & $26 \%$ \\
\hline 16 to 40 years old & $52 \%$ \\
\hline Over 40 years old & $22 \%$ \\
\hline \multicolumn{2}{|l|}{ Race } \\
\hline White & $12 \%$ \\
\hline Brown & $78 \%$ \\
\hline Black & $6 \%$ \\
\hline Indigenous & $4 \%$ \\
\hline \multicolumn{2}{|l|}{ Length of stay in endemic area } \\
\hline 0 to 10 years old & $22 \%$ \\
\hline 11 to 20 years old & $30 \%$ \\
\hline 21 to 30 years old & $14 \%$ \\
\hline 31 to 40 years old & $16 \%$ \\
\hline More than 40 years old & $18 \%$ \\
\hline \multicolumn{2}{|l|}{ Malaria in previous year } \\
\hline Yes & $52 \%$ \\
\hline No & $48 \%$ \\
\hline \multicolumn{2}{|l|}{ Lifelong malaria episodes } \\
\hline 1 to 5 & $36 \%$ \\
\hline 6 to 10 & $28 \%$ \\
\hline More than 10 & $36 \%$ \\
\hline \multicolumn{2}{|l|}{ Parasitemia } \\
\hline$<200$ parasites $/ \mathrm{mm}^{3}$ & $66 \%$ \\
\hline $200-300$ parasites $/ \mathrm{mm}^{3}$ & $10 \%$ \\
\hline $301-500$ parasites $/ \mathrm{mm}^{3}$ & $12 \%$ \\
\hline $501-10.000$ parasites $/ \mathrm{mm}^{3}$ & $12 \%$ \\
\hline
\end{tabular}

region (20\%). Before treatment, only $20 \%$ of patients reported dark urine, and no patient reported having had pale stools.

After initiation of treatment, a significant reduction in the prevalence of fever (38\%), arthralgia (26\%), back pain $(32 \%)$, and retroocular pain $(18 \%)(P<0.05$, Table 2$)$ was noted. However, there was significant increase in the frequency of nausea $(46 \%)$, diarrhea (26\%), pale stools (12\%), abdominal pain $(38 \%)$, bitter taste in the mouth $(60 \%)$, weakness $(36 \%)$, and hypochondrial pain $(32 \%)(P<0.05$, Table 2$)$. The frequency of choluria increased to $56 \%$ after initiation of antimalarial treatment $(P=0.01$, Table 2$)$. Other symptoms such as vomiting, loss of appetite, headache, myalgia, chills, and sweating, as well as respiratory symptoms and upper respiratory tract symptoms, suffered no major change in frequency (Table 2).

Among the adverse effects of chloroquine described in the literature and which are not often reported in malaria patients without treatment, there were reported changes in visual acuity (54\%), insomnia (46\%), pruritus (22\%), the feeling of "stings" into the skin (22\%), and paresthesias (6\%). No patient reported occurrence of seizures or unconsciousness after the start of antimalarial treatment. Most gastrointestinal symptoms appeared after the patient started the antimalarial treatment (Table 3).

\section{Discussion}

The symptoms most commonly seen in patients with malaria reported in the literature are fever, chills, sweating, headache, myalgia, and arthralgia. Da Silva-Nunes and Ferreira [14] evaluated 326 cases of untreated malaria, reporting high frequency of headache $(84.8 \%)$, fever $(80.9 \%)$, and myalgia $(68.7 \%)$, while gastrointestinal symptoms were infrequent $(<20 \%)$. In pregnant women with vivax or falciparum malaria, the most frequent symptoms were also fever (97.9\%), chills (71.7\%), and headache (62.4\%) [15].

The treatment of vivax malaria with chloroquine, a blood schizonticide, and primaquine (active against latent tissue forms of $P$. vivax or so-called hypnozoites) is very effective in reducing parasitemia and some of the symptoms caused by the Plasmodium infection, such as fever and algic symptoms. Fever tends to disappear between 24 and 48 hours after the beginning of treatment; parasitemia decreases significantly at about 48 to 72 hours, and pain symptoms decrease rapidly [16]. Pinto et al. [17] reported the disappearance of fever in $91.2 \%$ of patients, chills in $86 \%$ of patients, and headaches in $65.6 \%$ of patients at the end of the third day of treatment with chloroquine and primaquine and significant reduction of peripheral parasitemia between the second and third days of treatment.

However, chloroquine can cause side effects or intensify symptoms already present, such as abdominal discomfort, nausea, vomiting, and diarrhea. These side effects can also occur during the use of primaquine [16] being suitable to ingest the medication with food to avoid such side effects [18]. Chloroquine can rarely cause neurological symptoms, such as mental confusion, seizures, and coma, and cardiovascular symptoms such as hypotension, vasodilation, suppression of myocardial function, and cardiac arrhythmias, usually associated with rapid infusion of the drug parenterally. In usual doses for treatment of malaria, headache, blurred vision, and lichenoid rash can occur [16].

Chloroquine may block the entrance of potassium into the cells and primaquine also has an effect on blocking sodium channels. Both may also have an effect on the chloride channels present in cardiac myocytes, which may explain the occurrence of cardiac and gastrointestinal side effects [19]. In studies conducted in Belém (Pará), Silva et al. [20] found, as major side effects of chloroquine, the following symptoms: itching $(5.55 \%)$, epigastric pain $(1.28 \%)$, diarrhea $(0.85 \%)$, and choluria $(3.42 \%)$.

The itching and stinging sensation are explained by formation of haptens during the metabolism of chloroquine, which bind to degraded products erythrocytes or phospholipids involved in allergic reactions, stimulating the production of IgE-like antibodies and degranulation of mast cells and basophils. Also, the binding of chloroquine at the dermoepidermal junction may possibly result in stimulation of nerve fibers [21], causing these symptoms. 
TABLE 2: Malaria symptoms occurring before and after drug treatment.

\begin{tabular}{|c|c|c|c|c|c|}
\hline Symptoms & $N$ & $\%$ & Before medication & After the start of medication & Value of $P^{*}$ \\
\hline \multicolumn{6}{|l|}{ Gastrointestinal symptoms } \\
\hline Nausea & 50 & $44 \%$ & $22 \%$ & $46 \%$ & 0.012 \\
\hline Vomiting & 50 & $62 \%$ & $16 \%$ & $24 \%$ & 0.481 \\
\hline Diarrhea & 50 & $72 \%$ & $4 \%$ & $26 \%$ & 0.003 \\
\hline Pale stools & 50 & $88 \%$ & $0 \%$ & $12 \%$ & 0.031 \\
\hline Loss of appetite & 50 & $44 \%$ & $32 \%$ & $46 \%$ & 0.143 \\
\hline Mesogastric and/or hypogastric pain & 50 & $48 \%$ & $20 \%$ & $38 \%$ & 0.017 \\
\hline Bitter taste in the mouth & 50 & $30 \%$ & $30 \%$ & $60 \%$ & 0.004 \\
\hline Pain in hypochondria & 50 & $62 \%$ & $14 \%$ & $32 \%$ & 0.035 \\
\hline \multicolumn{6}{|l|}{ Algic symptoms } \\
\hline Headache & 49 & $14 \%$ & $76 \%$ & $70 \%$ & 0.581 \\
\hline Myalgia & 50 & $58 \%$ & $30 \%$ & $22 \%$ & 0.454 \\
\hline Arthralgia & 50 & $42 \%$ & $48 \%$ & $26 \%$ & 0.007 \\
\hline Lower back pain & 50 & $40 \%$ & $52 \%$ & $32 \%$ & 0.031 \\
\hline Retroocular pain & 50 & $60 \%$ & $36 \%$ & $18 \%$ & 0.022 \\
\hline \multicolumn{6}{|l|}{ General symptoms } \\
\hline Fever & 50 & $20 \%$ & $72 \%$ & $38 \%$ & 0.001 \\
\hline Chills & 50 & $34 \%$ & $54 \%$ & $34 \%$ & 0.052 \\
\hline Sweating & 50 & $36 \%$ & $54 \%$ & $40 \%$ & 0.143 \\
\hline Weakness/malaise & 50 & $22 \%$ & $42 \%$ & $64 \%$ & 0.043 \\
\hline \multicolumn{6}{|l|}{ Other symptoms } \\
\hline Itching throat & 50 & $90 \%$ & $4 \%$ & $8 \%$ & 0.625 \\
\hline Jaundice & 50 & $86 \%$ & $8 \%$ & $14 \%$ & 0.250 \\
\hline Choluria & 50 & $36 \%$ & $20 \%$ & $56 \%$ & 0.001 \\
\hline Dyspnea & 50 & $84 \%$ & $4 \%$ & $14 \%$ & 0.125 \\
\hline
\end{tabular}

${ }^{*}$ McNemar's test.

TABLE 3: Side effects of chloroquine and primaquine in treated patients with vivax malaria.

\begin{tabular}{llcc}
\hline Drug & Symptom & $N$ & $\%$ \\
\hline \multirow{3}{*}{$\begin{array}{l}\text { Chloroquine/ } \\
\text { primaquine }\end{array}$} & Nausea & 16 & $32 \%$ \\
& Domiting & 11 & $22 \%$ \\
& Pale stools & 12 & $24 \%$ \\
& Bitter taste in the mouth & 6 & $12 \%$ \\
& Pain in hypochondria & 12 & $40 \%$ \\
\hline \multirow{3}{*}{ Chloroquine } & Blurred vision (3 d) & 27 & $54 \%$ \\
& Pruritus (3 d) & 11 & $22 \%$ \\
& "Stinging" skin (3 d) & 11 & $22 \%$ \\
& Convulsion (3 d) & 0 & $0 \%$ \\
& Paresthesia (3 d) & 3 & $6 \%$ \\
& Insomnia (3 d) & 23 & $46 \%$ \\
\hline \multirow{3}{*}{ Primaquine } & Lack of appetite & 12 & $24 \%$ \\
& Meso- or hypogastric pain & 16 & $32 \%$ \\
& Choluria & 22 & $44 \%$ \\
& Weakness/malaise & 18 & $36 \%$ \\
\hline
\end{tabular}

Regarding primaquine use, the most prevalent side effect is hemolytic anemia, resulting in jaundice and choluria. Weakness, malaise, and abdominal pain are also reported as primaquine side effects. Data on primaquine use worldwide indicates that, among 200 million people, there were 14 deaths in six decades related to its use, from which 12 were caused by severe hemolysis [22]. Hemolytic anemia can also occur in people without G6PD deficiency when using primaquine, although it is a very scarce event [22].

The gene encoding the G6PD is located on the X chromosome (locus Xq28), with a recessive pattern of inheritance linked to sex. It can manifest as homozygous or heterozygous inheritance in females and hemizigous in males [23]. In heterozygous females normal red blood cells can coexist with red blood cells deficient in G6PD, in variable proportion [7], and this can cause a milder hemolytic anemia when exposed to primaquine. At the same time, there are 180 different genetic variants of G6PD, resulting in different levels of hemolysis [24]. The Mediterranean variant, which predominates in Europe, Western and Central Asia, and North of India, is more severe, while the African variant (common in sub-Saharan Africa, Amazon, and Afro-Americans) is a milder variant [25]. In these milder variants, hemolysis will be clinically detected only after one or two days of exposure to primaquine [25]. 
The prevalence of G6PD deficiency is between 3 and $30 \%$ in endemic countries for malaria, corresponding to 350 million people [22]. In the Americas, it has a lower prevalence, varying between 5 and $10 \%$ in the Amazon region and higher levels in tropical Africa, Middle East, and the Mediterranean basin [26], such as Sudan and Congo, where it is present in more than $20 \%$ of the population [27]. In Brazil, the frequency of G6PD deficiency varies between $1.7 \%$ and $6.0 \%$, prevailing the African variant [28]. In Manaus, a city with high levels of transmission of malaria in the Brazilian Amazon, the prevalence of G6PD was 2.5\% [28]. This difference in prevalence may explain why, in Brazil, primaquine is administered to all nonpregnant patients older than 6 months with an unknown G6PD deficiency status, while in other countries with higher prevalence of this enzymatic deficiency (or in which more severe variants are common) primaquine use is very much debated and controversial [29].

The consequences of severe hemolysis are severe anemia and acute renal insufficiency. These events are dependent on the extent of hemolysis, which is related to the severity of G6PD deficiency and the dose of primaquine [26]. Recommended primaquine doses used to block falciparum malaria transmission $(0.25 \mathrm{mg}$ of base per kilogram) are usually considered to have low toxicity, because it is a single-dose treatment [26]. However, primaquine use in vivax malaria, aimed at preventing relapsing events, is a longer course (between 7 and 14 days), with varying dosage among malaria control policies, and therefore hemolytic events are more prone to happen [22].

In a systematic revision, Monteiro et al. [26] detected 47 cases of hemolytic anemia in patients using primaquine in Latin America and Caribbean, and 23 occurred in Brazil. However, Brazil has the largest population at risk for malaria; thus it is expected to have more cases reported. A few cases of primaquine-induced hemolysis have also been reported in other countries, such as Cuba, El Salvador, Puerto Rico, and Trinidad and Tobago, between 1963 and 2013.

In our study, the frequency of choluria ("dark urine") increased significantly from $6 \%$ to $56 \%$ in malaria patients after primaquine was started. Since it is an event referred by the patient, we cannot be sure how many of the patients really presented with choluria, or how severe was the choluria, but it is known that G6PD deficiency occurs among Amazonian residents. Malaria and weakness also increased significantly from $42 \%$ to $64 \%$ after primaquine use. It is possible that the hemolytic anemia is the cause of weakness and malaise, reported by these patients. However, none of the patients studied suffered from severe hemolysis or severe anemia (data not shown) or required hospitalization during or after malaria treatment. Although severe events related to the use of primaquine were infrequent in our and other studies in the Amazon, it is important to bear in mind the possible adverse side effects of primaquine and also mild anemia occurring in patients with the less severe forms of G6PD deficiency, which can be associated or not with weakness. Kondrashin et al. [30] reported that subjects with no G6PD deficiency showed reduction of 1 to $2 \mathrm{~g} / \mathrm{dL}$ of hemoglobin after primaquine use, while in G6PD deficient patients hemoglobin levels decreased between 3 and $5 \mathrm{~g} / \mathrm{dL}$, with fast normalization after treatment was over.

Smithuis et al. reported abdominal pain as a side effect for primaquine in falciparum malaria patients from Myanmar, occurring in $16 \%$ of patients receiving a single dose. There is no clear evidence why primaquine can cause abdominal pain; it can be related to the direct effect of the drug on an empty stomach [31] or related to the release of pharmacological substances during hemolysis. Despite its cause, it is noteworthy that, in our study, abdominal pain increased significantly from $6 \%$ to $32 \%$ after primaquine was started.

Although the present study has a limitation in the number of subjects studied, it was possible to detect significant association of symptoms and malaria treatment. Thus, while the treatment of vivax malaria with a combination of chloroquine and primaquine leads to decrease in fever and pain symptoms, it can lead to the onset of gastrointestinal symptoms and hemolysis or enhances these symptoms when already present in the patient with malaria, contributing to reducing treatment adherence, especially during the use of primaquine, which has a longer course of treatment. Moreover, the sensation of itching and stinging, although they do not occur in all patients, can be quite intense, hindering treatment with chloroquine. It is important to warn the patient of these possible side effects and seek measures to minimize them, either with concomitant use of antihistamines or antiemetics, according to the individual needs of each patient. The occurrence of severe hemolysis after primaquine use, although not common in Brazil, can still occur, and since Brazilian control programs currently do not have a policy for G6PD deficiency screening before malaria treatment is offered, health care personnel must be aware of it to interrupt primaquine use and manage its side effects properly.

\section{Conflict of Interests}

The authors declare that there is no conflict of interests regarding the publication of this paper.

\section{Authors' Contribution}

Cássio Braga e Braga, Antonio Camargo Martins, Wagner de Jesus Pinto, and Mônica da Silva-Nunes designed the study. Cássio Braga e Braga, Athaid David Escalante Cayotopa, and Antonio Camargo Martins selected study participants in microscopy units. Cássio Braga e Braga, Wagner Werner Klein, Aline Ferreira da Silva, Mardelson Nery de Souza, Breno Wilson Benevides Andrade, and José Alcântara Filgueira-Júnior performed the data collection and data processing. Cássio Braga e Braga conducted all clinical interviews and performed the statistical analysis, supervised by Mônica da Silva-Nunes. Cássio Braga e Braga and Mônica da Silva-Nunes wrote the paper, which was reviewed and approved by other authors.

\section{Acknowledgments}

The authors thank the population and local authorities for research assistance, the Secretary of Health of Mâncio 
Lima, Mr. Josianis Araújo Rodrigues, Mr. Neilson Melo, from the local Malaria Control program, and Ms. Thayna Holanda, from the State Secretary of Health, for their support of field activities. The authors thank the endemic agents of the municipality of Mâncio Lima who kindly cooperated in locating the patients. The authors Cássio Braga e Braga, Antonio Camargo Martins, Andreus Roberto Schlosser, Wagner Werner Klein, Aline Ferreira da Silva, Mônica da Silva-Nunes, Breno Wilson Benevides Andrade, and José Alcântara Filgueira-Júnior received undergraduate research grant from $\mathrm{CNPq}$ and/or UFAC. This work was supported by the Federal University of Acre (UFAC, Brazil) and Fundação de Amparo à Pesquisa do Acre (FAPAC, Brazil) through the Research Program for SUS Announcement MS/CNPq/FDCT-FUNTAC/SESACRE 2013.

\section{References}

[1] P. Hindi, World Malaria Report 2010, 2010, http://www.who .int/malaria/world_malaria_report_2010/en/.

[2] P. W. Gething, A. P. Patil, D. L. Smith et al., "A new world malaria map: Plasmodium falciparum endemicity in 2010," Malaria Journal, vol. 10, no. 1, article 378, 2011.

[3] I. Mueller, P. A. Zimmerman, and J. C. Reeder, "Plasmodium malariae and Plasmodium ovale - the 'bashful' malaria parasites," Trends in Parasitology, vol. 23, no. 6, pp. 278-283, 2007.

[4] J. J. Van Hellemond, M. Rutten, R. Koelewijn et al., "Human Plasmodium knowlesi infection detected by rapid diagnostic tests for malaria," Emerging Infectious Diseases, vol. 15, no. 9, pp. 1478-1480, 2009.

[5] A. P. Gomes, R. R. Vitorino, A. D. P. Costa, E. G. De Mendonça, M. G. D. A. Oliveira, and R. Siqueira-Batista, "Malária grave por Plasmodium falciparum," Revista Brasileira de Terapia Intensiva, vol. 23, no. 3, pp. 358-369, 2011.

[6] B.-M. da Saúde, Guia prático de tratamento da malária no Brasil, Brasília-DF, 1st edition, 2010, http://www.google.com.br/url? $\mathrm{sa}=\mathrm{t} \& \mathrm{rct}=\mathrm{j} \& \mathrm{q}=\& \mathrm{esrc}=\mathrm{s} \&$ source $=$ web $\& \mathrm{~cd}=1 \& \mathrm{sq} \mathrm{i}=2 \& v e d=0 \mathrm{CB}$ 0QFjAA\&url=ftp://ftp.cve.saude.sp.gov.br/doc_tec/zoo/malaria 10_guia_tratamento.pdf\&ei=71pRVfzIO4ScgwSM6oHYCg\&usg =AFQjCNF9wRnUq181Ar3ysE_ryPn2-4e6Ag\&bvm=bv.928851 02.

[7] B. Barraviera, D. A. Meira, P. E. de Abreu Machado, and P. R. Curi, "Malária no município de Humaitá, estado do Amazonas. XXI. Prevalência da deficiência de glicose-6-fosfato desidrogenase (G6PD) Em amostra da população e em doentes com malaria causada pelo Plasmodium falciparum," Revista do Instituto de Medicina Tropical de São Paulo, vol. 29, no. 3, pp. 374-380, 1987.

[8] A. S. Alving, C. F. Johnson, A. R. Tarlov, G. J. Brewer, R. W. Kellermeyer, and P. E. Carson, "Mitigation of the haemolytic effect of primaquine and enhancement of its action against exoerythrocytic forms of the Chesson strain of Plasmodium vivax by intermittent regimens of drug administration: a preliminary report," Bulletin of the World Health Organization, vol. 22, no. 6, pp. 621-631, 1960.

[9] M. Davanco, "Evaluation of antimalarial activity and toxicity of a new primaquine prodrug," PLoS ONE, vol. 9, no. 8, Article ID e105217, 10 pages, 2014.

[10] D. R. Hill, J. K. Baird, M. E. Parise, L. S. Lewis, E. T. Ryan, and A. J. Magill, "Primaquine: report from CDC expert meeting on malaria chemoprophylaxis I," The American Journal of Tropical Medicine and Hygiene, vol. 75, no. 3, pp. 402-415, 2006.

[11] R. B. Melles and M. F. Marmor, "Pericentral retinopathy and racial differences in hydroxychloroquine toxicity," Ophthalmology, vol. 122, no. 1, pp. 110-116, 2015.

[12] M. A. Al-Bari, "Chloroquine analogues in drug discovery: new directions of uses, mechanisms of actions and toxic manifestations from malaria to multifarious diseases," Journal of Antimicrobial Chemotherapy, 2015.

[13] W. Alberto, S. Giraldo, M. G. Platero, C. De, P. Bujidos, and L. Gámir, "Hiperpigmentación cutánea generalizada y melanoniquia longitudinal secundarias al tratamiento con hidroxicloroquina en lupus eritematoso sistémico," Reumatol Clínica, vol. 9, no. 6, pp. 381-382, 2013.

[14] M. da Silva-Nunes and M. U. Ferreira, "Clinical spectrum of uncomplicated malaria in semi-immune Amazonians: beyond the 'symptomatic' vs 'asymptomatic' dichotomy," Memórias do Instituto Oswaldo Cruz, vol. 102, no. 3, pp. 341-347, 2007.

[15] R. Jarude, R. Trindade, and J. Tavares-Neto, "Malária em grávidas de uma maternidade pública de Rio Branco (Acre, Brasil)," Revista Brasileira de Ginecologia e Obstetrícia, vol. 25, no. 3, pp. 149-154, 2003.

[16] L. S. Goodman and A. G. Gilman, As bases farmacológicas da terapêutica, McGraw-Hill Medical, Rio de Janeiro, Brazil, 12th edition, 2011.

[17] A. Y. D. N. Pinto, C. H. Azevedo, J. B. Da Silva, and J. M. De Souza, "Assessment of chloroquine single dose treatment of malaria due to Plasmodium vivax in Brazilian Amazon," Revista Instituto de Medicina Tropical de São Paulo, vol. 45, no. 6, pp. 327-331, 1859.

[18] D. Fernando, C. Rodrigo, and S. Rajapakse, "Primaquine in vivax malaria: an update and review on management issues," Malaria Journal, vol. 10, no. 1, article 351, 2011.

[19] M. Wagner, K. G. Riepe, E. Eberhardt, and T. Volk, "Open channel block of the fast transient outward $\mathrm{K}^{+}$current by primaquine and chloroquine in rat left ventricular cardiomyocytes," European Journal of Pharmacology, vol. 647, no. 1-3, pp. 13-20, 2010.

[20] R. d. Silva, A. Y. Pinto, V. S. Calvosa, and J. M. Souza, "Esquemas terapêuticos encurtados para o tratamento de malária por Plasmodium vivax," Revista da Sociedade Brasileira de Medicina Tropical, vol. 36, no. 2, pp. 235-239, 2003.

[21] S. E. Aghahowa, H. O. Obianwu, A. O. Isah, and I. M. Arhewoh, "Chloroquine-induced pruritus," Indian Journal of Pharmaceutical Sciences, vol. 72, no. 3, pp. 283-289, 2010.

[22] E. A. Ashley, J. Recht, and N. J. White, "Primaquine: the risks and the benefits," Malaria Journal, vol. 13, no. 1, article 418, 2014.

[23] T. H. Katsuragawa, R. P. D. A. Cunha, D. C. A. De Souza et al., "Malária e aspectos hematológicos em moradores da área de influência dos futuros reservatórios das hidrelétricas de Santo Antônio e Jirau, Rondônia, Brasil," Cadernos de Saúde Pública, vol. 25, no. 7, pp. 1486-1492, 2009.

[24] M. Cappellini and G. Fiorelli, "Glucose-6-phosphate dehydrogenase deficiency," The Lancet, vol. 371, no. 9606, pp. 64-74, 2008.

[25] E. Beutler, "G6PD deficiency," Blood Journal, vol. 84, no. 11, pp. 3613-3636, 1994.

[26] W. M. Monteiro, G. P. Franca, G. C. Melo et al., "Clinical complications of G6PD deficiency in Latin American and Caribbean populations: systematic review and implications for malaria elimination programmes," Malaria Journal, vol. 13, article 70, 2014. 
[27] R. E. Howes, F. B. Piel, A. P. Patil et al., "G6PD deficiency prevalence and estimates of affected populations in malaria endemic countries: a geostatistical model-based map," PLoS Medicine, vol. 9, no. 11, Article ID e1001339, 2012.

[28] M. S. Santana, M. V. G. de Lacerda, M. D. G. V. Barbosa, W. Duarte Alecrim, and M. D. G. Costa Alecrim, "Glucose6-phosphate dehydrogenase deficiency in an endemic area for malaria in Manaus: a cross-sectional survey in the Brazilian Amazon," PLoS ONE, vol. 4, no. 4, pp. 4-7, 2009.

[29] K. Baird, "Origins and implications of neglect of G6PD deficiency and primaquine toxicity in Plasmodium vivax malaria," Pathogens and Global Health, vol. 109, no. 3, pp. 93-106, 2015.

[30] A. Kondrashin, A. M. Baranova, E. A. Ashley, J. Recht, N. J. White, and V. P. Sergiev, "Mass primaquine treatment to eliminate vivax malaria: lessons from the past," Malaria Journal, vol. 13, article 51, 2014

[31] F. Smithuis, M. K. Kyaw, O. Phe et al., "Effectiveness of five artemisinin combination regimens with or without primaquine in uncomplicated falciparum malaria: an open-label randomised trial," The Lancet Infectious Diseases, vol. 10, no. 10, pp. 673-681, 2010. 


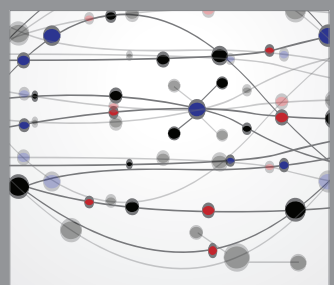

The Scientific World Journal
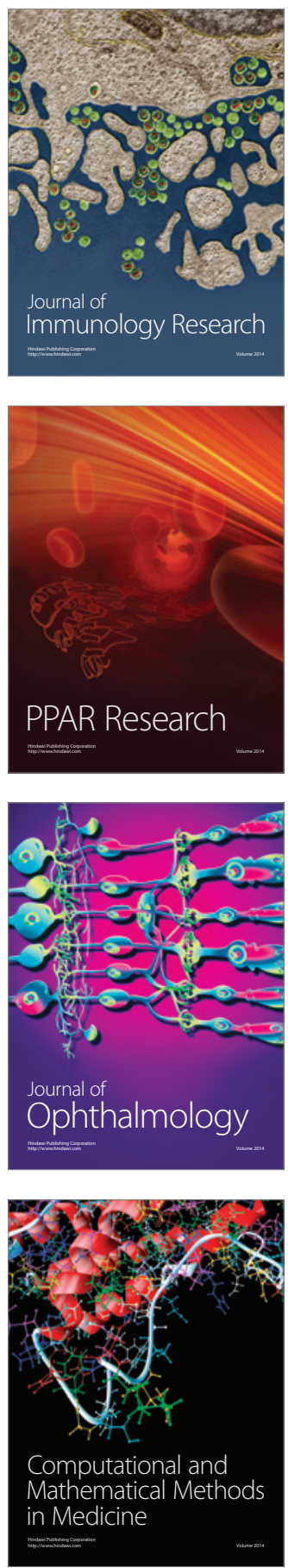

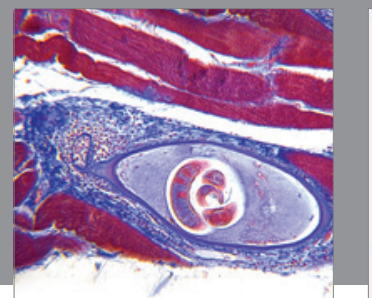

Gastroenterology

Research and Practice
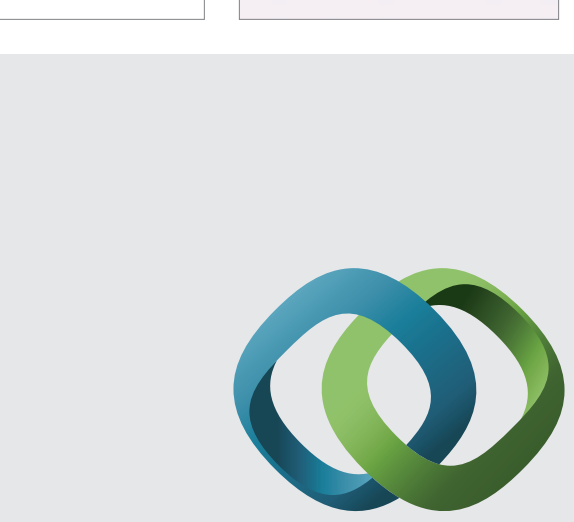

\section{Hindawi}

Submit your manuscripts at

http://www.hindawi.com
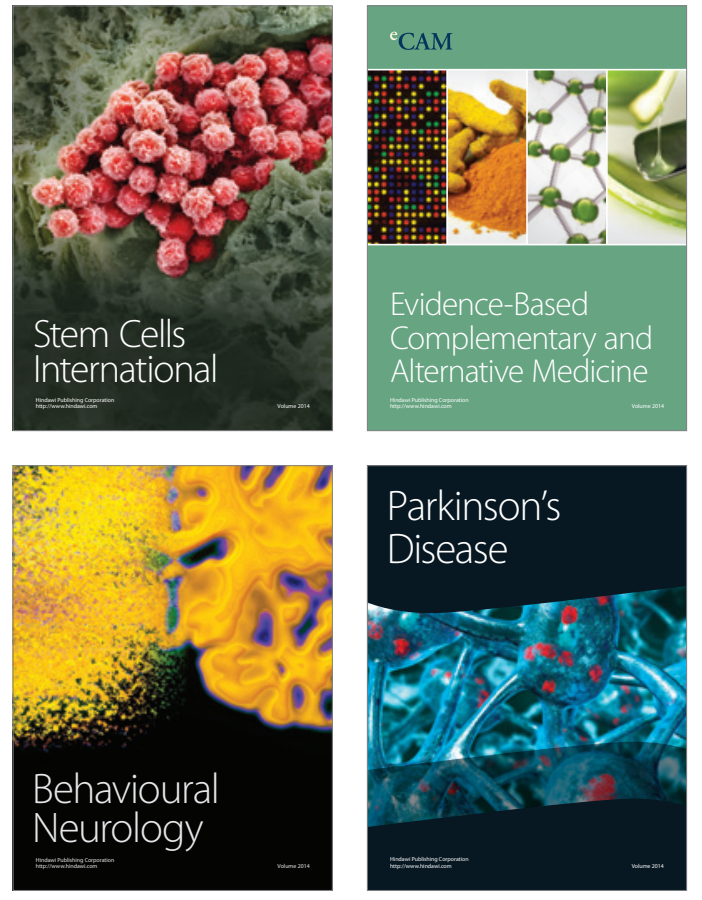
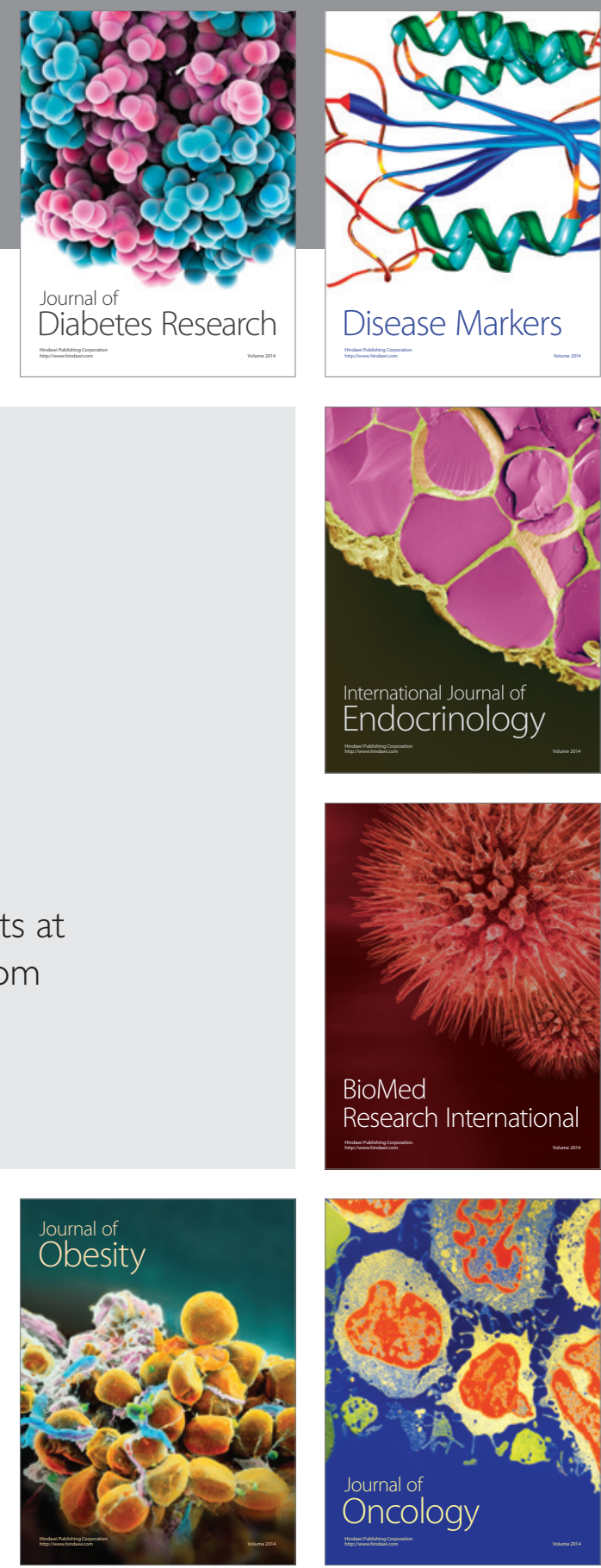

Disease Markers
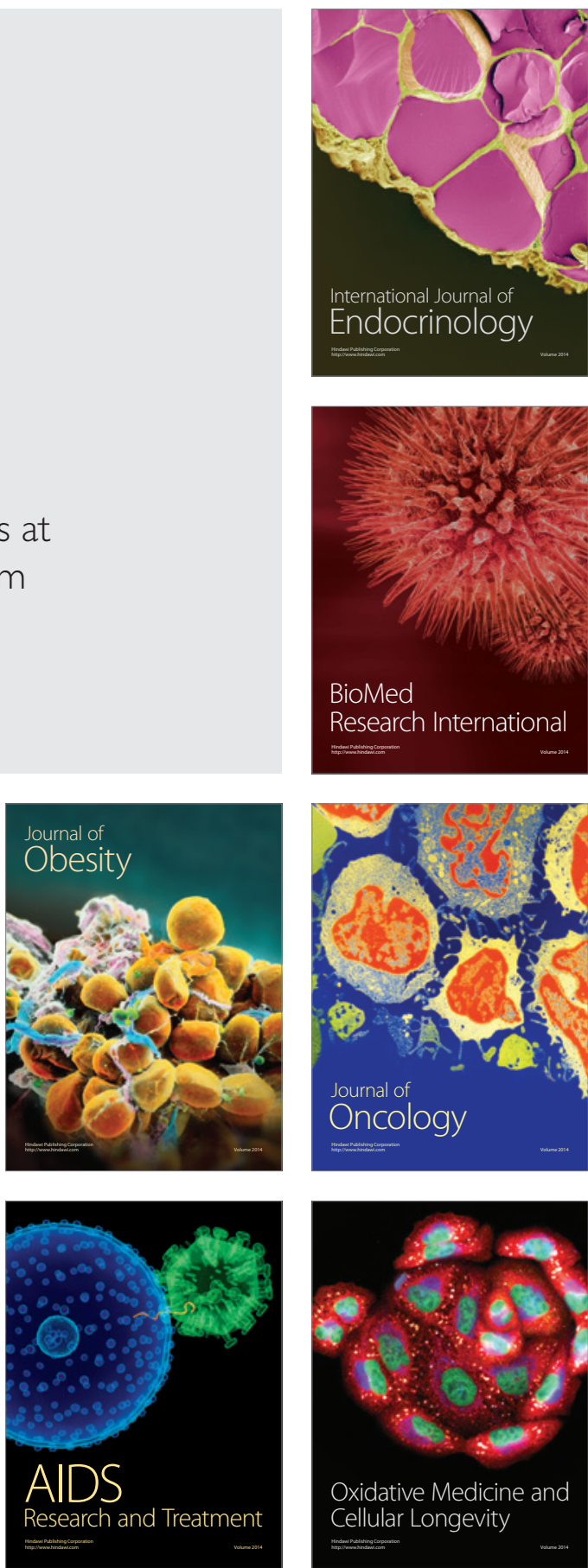